\title{
Utilization of The Museum af Kekhatuan Semaka as a Source of Learning in Local History
}

\author{
Andre Mustofa Meihan, Sariyatun, Deny Tri Ardianto \\ Universitas Sebelas Maret \\ andremustofameihan@gmail.com
}

\author{
Article History \\ accepted 1/09/2020
}

approved 4/10/2020

published 1/12/2020

\begin{abstract}
The purpose of this study was to determine: 1) Management and types of collections at the Kekhatuan Semaka Museum; 2) Utilization of the kekhatuan semaka museum collection as a source of historical learning; 3) The Museum's strategy for self-promotion. The research method used is descriptive qualitative. The data collection techniques used were literature study, interview, observation, and documentation. The object of research is Kekhatuan semaka Museum. The data analysis technique used is interaction analysis, with four stages, namely data collection, data reduction, data presentation, and drawing conclusions or verification. Based on the results of the discussion, it can be concluded that: 1) The management of the kekhatuan semaka museum is carried out independently by the museum owner and the museum collection includes historical heritage objects and objects of Lampung culture; 2) The use of the Khatuan semaka Museum Collection as a source of historical learning is by linking it with KD and history learning materials; 3) The form of promotion carried out by the kekhatuan semaka museum through social media and annual festivals.
\end{abstract}

Keywords: Utilization, museum, kekhatuan semaka, historical sources.

\section{Abstrak}

Tujuan penelitian ini adalah untuk mengetahui: 1) Pengelolaan dan Jenis-jenis koleksi museum kekhatuan semaka; 2) Pemanfaatan koleksi museum kekhatuan semaka sebagai sumber belajar sejarah; 3) Strategi Museum kekhatuan semaka dalam mempromosikan diri. Metode penelitian yang digunakan adalah kualitatif deskriptif. Teknik pengumpulan data yang digunakan yaitu studi pustaka, wawancara, observasi, dan dokumentasi. Objek penelitian adalah museum kekhatuan semaka. Teknik analisis data yang digunakan adalah analisis interaksi, dengan empat tahapan yaitu pengumpulan data, reduksi data, penyajian data, dan penarikan simpulan atau verifikasi. Berdasarkan hasil pembahasan dapat disimpulkan bahwa: 1) Pengelolaan museum kekhatuan semaka dilakukan oleh pemilik museum secara mandiri dan Koleksi museum meliputi bendabenda peninggalan sejarah dan benda-benda hasil kebudayaan lampung; 2) Pemanfaatan koleksi museum kekhatuan semaka sebagai sumber belajar sejarah adalah dengan mengaitkannya dengan KD dan materi pembelajaran sejarah; 3) Bentuk promosi yang dilakukan museum kekhatuan semaka melalui media sosial dan festival tahunan.

Kata kunci: Pemanfaatan, Museum, kekhatuan semaka, sumber sejarah.

Social, Humanities, and Education Studies (SHEs): Conference Series https://jurnal.uns.ac.id/shes 


\section{PENDAHULUAN}

Pendidikan merupakan suatu kegiatan sosial budaya yang mencakup masyarakat hingga suatu bangsa dalam membentuk dan mengembangkan kualitas warganegaranya untuk kehidupan pada masa sekarang maupun masa yang akan datang (Hasan, 2012). Sehingga semakin berkualitas pendidikan disebuah negara maka akan semakin baik pula masa depan bangsa tersebut. Karena pendidikan adalah sebuah invesatasi jangka panjang bagi suatu negara. salah satu inti dari tujuan pendidikan nasional adalah mengembangkan potensi peserta didik agar menjadi manusia yang berkualitas. Salah satu mata pelajaran yang memiliki peran yang besar dalam tercapainya tujuan pendidikan nasional adalah pendidikan sejarah.

Pendidikan sejarah didalamnya menggambarkan peristiwa-peristiwa yang telah terjadi pada lampau dan mengungkap berbagai makna yang berguna untuk perjuanganpada masa kini dan untuk memperoleh masa yang akan datang. Di era globalisasi saat ini, pendidikan sejarah memiliki peran yang sangat besar dalam menjaga identitas suatu bangsa. peran strategis pendidikan sejarah untuk menumbuhkan kembali kesadaransejarah bangsa Indonesia dalam menghadapi krisis multidimensional terlihat sangat jelas (Susrianto, 2012). Dimana dalam meteri-materi sejarah akan diajarakan kepada para peserta didik mengenai rasa nasionalisme dan patriotisme pada bangsa dan negara.

Namun nyatanya pembelajaran sejarah di sekolah masih terdapat banyak masalah. Permasalahan dalam pembelajaran sejarah di sekolah adalah terdapat pandangan yang sangat kuat di kalangan peserta didik bahwasannya mata pelajaran sejarah adalah mata pelajaran yang bersifat hafalan, kurang menarik, dan membosankan (Sayono, 2015). Ditambah lagi Dalam proses pembelajaran sejarah, masih banyak guru menggunkan teknik pembelajaran secara konvensional, yaitu guru menjelaskan dan murid mendengarkan (Subakti, 2010). Kurangnya inovasi dalam pembelajaran sejarah membuat siswa menjadi tidak bersemangat dalam belajar sejarah. pemilihan media pembelajaran sejarah disekolah pun kenyataannya masih terbatas pada penggunaan buku teks, LKS, dan Powerpoint yang cenderung membosankan (Meihan, 2019).

Sehingga harus ada terobosan dalam mengajarkan sejarah guna pembelajaran menjadi lebih menarik. Salah satunya dengan memanfaatkan media museum sebagai sarana belajar sejarah. Sudah kita ketahui bahwa museum memiliki fungsi sebagai penyimpan benda-benda besejarah yang dapat dijadikan sebagai sarana belajar oleh peserta didik. Menurut ICOM pengertian museum merupakan suatu lembaga yang bersifat tetap, tidak mencari keuntungan, melayani masyarakat dan perkembangannya, terbuka untuk umum, memperoleh, merawat, menghubungkan dan memamerkan untuk tujuan studi, pendidikan, dan kesenangan, barang pembuktian manusia dan lingkungannya (Asmara, 2019). Lebih lanjut lagi Asmara, (2019), menjelaskan bahwa fungsi museum selalu mengalami perubahan dari masa kemasa sesuai dengan situasi dan kondisi, tetapi hakikatnya pengertian museum itu tidak berubah.

Salah satu museum yang dapat dijadikan sumber belajar sejarah adalah museum kekhatuan semaka. Museum kekhatuan semaka merupakan sebuah museum mini yang berada di kabupaten Tanggamus, Provinsi Lampung. Museum ini memiliki banyak sekali benda-benda bersejarah yang ada di lampung (Meihan, et.al, 2020). Museum ini sangat menarik dan cocok untuk dijadikan salah satu objek belajar sejarah lokal. Keberadaan museum ini bisa menjadi suatu tempat wisata sejarah di daerah kabupaten Tanggamus, lampung. Belajar sejarah bisa memanfaatkan benda-benda yang ada di lingkungan sekitar para peserta didik, salah satunya dengan mempelajari koleksi yang ada pada museum kekhatuan semaka. Dengan memanfaatkan museum sebagai sumber belajar sejarah lokal, tentunya akan membentuk jati diri bangsa, baik 
melalui kesadaran budaya ataupun kesadaran sejarah (Romadi \& Kurniawan, 2017). Berdasarkan pembahasan tersebut, dalam artikel ini akan dibahas mengenai bagaimana pemanfaatan museum kekhatuan semaka sebagai sumber belajar sejarah lokal.

\section{METODE}

Sugiyono (2017) menjelasakan bahwa metode adalah cara ilmiah dalam memperoleh data dengan tujuan dan guna tertentu. Selanjutnya pendapat lain menjelaskan bahwa Metode penelitian yaitu tata cara bagaimana suatu penelitian dapat dilaksanakan (Hasan, 2012). Sehingga dapat disimpulkan metode penelitian adalah suatu cara-cara atau langkah ilmiah yang dapat digunakan untuk memproleh data dengan tujuan tertentu.

Metode penelitian yang digunakan adalah kualitatif deskriptif. metode deskriptif digunakan dalam mendeskripsikan dan menginterpretasikan suatu permasalahan yang ada, seperti keadaan dan hubungan yang ada, pendapat yang sedang tumbuh, suatu proses yang tengah berlangsung, dampak yang terjadi atau kecenderungan yang tengah berkembang (Sumanto, 2014).

Teknik pengumpulan data yang digunakan yaitu studi pustaka, wawancara, observasi, dan dokumentasi. Objek penelitian dalam penelitian ini adalah museum kekhatuan semaka. Teknik analisis data yang digunakan adalah analisis interaksi, dengan empat tahapan yaitu pengumpulan data, reduksi data, penyajian data, dan penarikan simpulan atau verifikasi (Miles M.B \& Huberman A.M, 1992).

\section{HASIL DAN PEMBAHASAN}

\section{Pengelolaan dan Jenis-Jenis Koleksi Museum Kekhatuan Semaka}

Museum memiliki peranan yang besar dalam menjaga benda-benda bersejarah. Selain itu museum juga berperan dalam pelestarian hasil kebudayaan di suatu tempat. dimana dalam sebuah museum akan disimpan dan dikelola bermacam-macam bendabenda warisan budaya secara baik, dan akan menjadi pembelajaran bagi para penerus bangsa. Setiap benda yang menjadi koleksi museum tentunya sesuatu yang dianggap penting. Hal tersebut senada dengan pemdapat Sumadio (1997) yang menyatakan bahwa benda koleksi sebuah museum tentunya diangap penting dan menimbulkan kebanggaan bagi pemiliknya. Oleh karena itu, warisan kebudayaan yang dihasilkan harus dilestarikan dan dipamerkan kepada khalayak umum (Suutarga, 1990). Kesemuanya itu juga telah dilakukan oleh meuseum kekhatuan semaka.

Museum yang didirikan sejak tahun 2015 ini menjadi salah satu tempat pelesatarian benda-benda warisan budaya yang ada di Lampung, khusususnya di Kabupaten Tanggamus. Museum ini dimiliki oleh bapak Abu Sahlan yang bergelar Pangeran Khatu Semaka sebagai keturunan ke 13 dari kekahtuan semaka. Museum ini didirikan atas inisiatif keluarga besar kekhatuan semaka untuk mengumpulkan bendabenda bersejarah peninggalan kekhatuan semaka. Barulah, pada bulan April 2015 museum ini dibuka secara resmi atas Kerjasama dengan pihak swasta PT. Natarang Mining.

Pengelolaan museum kekhatuan semaka yang meliputi kegiatan pengadaan koleksi museum, kegiatan penempatan koleksi, pengamanan koleksi, dan penyediaan tempat koleksi masih bersifat sederhana dan dilakukan oleh pemilik museum langsung secara mandiri. Sebagaimana yang disampaikan oleh pemilik museum, "... perawatan benda-benda koleksi museum kehatuan semaka dilakukan sendiri dengan dana pribadi" (Wawancara Pribadi AS, 21 Januari 2020).

Koleksi yang ada di museum kekahtuan semaka beranekaragam baik bendabenda bersejarah sampai benda-benda hasil warisan budaya lampung. Berdasarkan penuturan informan, "...untuk koleksi yang ada di museum kekhatuan semaka beraneka ragam mulai dari benda-benda masa pemujaan, benda-benda peninggalan kesultanan 
banten, dan benda-benda khas Lampung" (Wawancara Pribadi AS, 21 Januari 2020). Beberapa koleksi museum kekhatuan semaka sebagai berikut:

a. Apai Kelingi

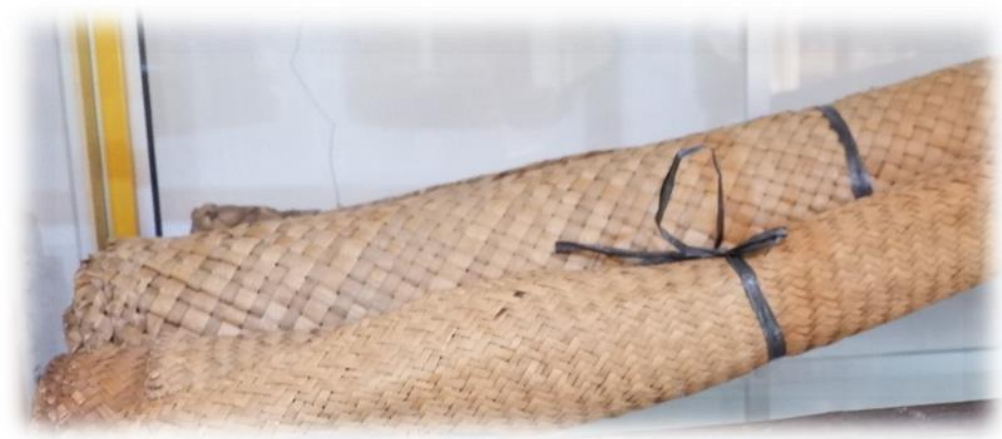

Sumber: Dokumentasi peneliti 2020

Gambar 1. Apai Kelingi

Apai kelingi merupakan tikar yang dianyam dari batang kelingi yang tumbuh di rawarawa dan bisanya dugunakan untuk duduk oleh ulun lampung zaman dulu.

b. Tuping Sakura

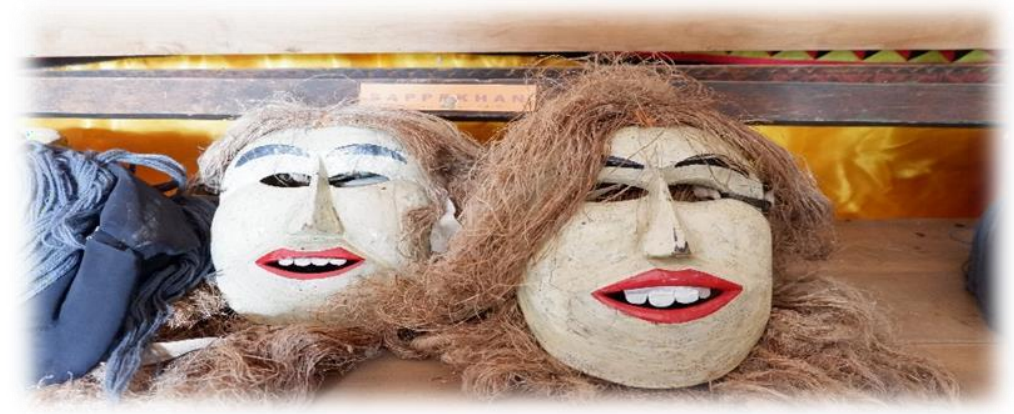

Sumber: Dokumentasi peneliti 2020

Gambar 2. Tuping Sakura

Tuping sakura merupakan topeng yang sering digunakan dalam memriahkan acaraacara seperti pementasan drama tupping, sekuraan dan parade topeng.

c. Cicih

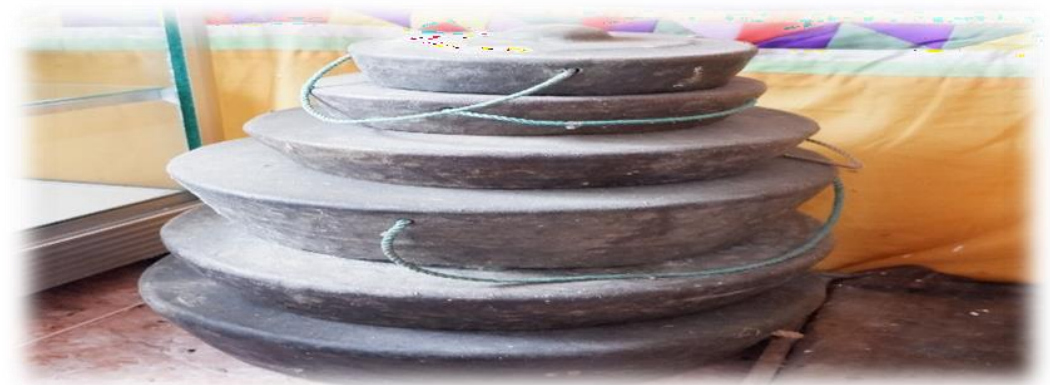

Sumber: Dokumentasi peneliti 2020 


\section{Gambar 3. Cicih}

Cicih merupakan alat musik tradisional lampung yang biasnya digunakan untuk mengiringi acara kegiatan-kegiatan adat, tarian tradisonal lampung, dan seni bela diri lampung.

d. Batu-Batu Masa Animisme Dan Dinamisme

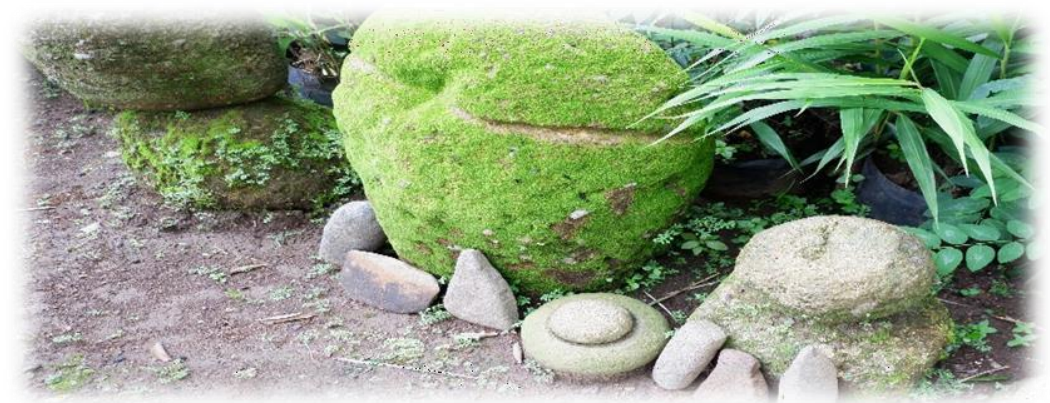

Sumber: Dokumentasi peneliti 2020

Gambar 4. Batu Masa Animisme dan Dinamisme

Batu-batu peninggalan masa animisme dan dinamisme yang masih terlihat baik dalam museum kekhatuan semaka.

e. Mangkok Birma

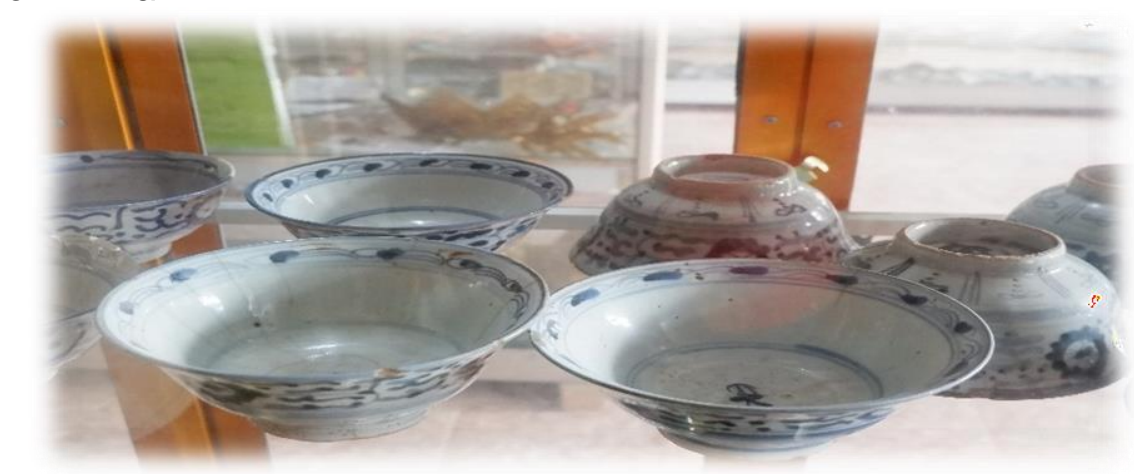

Sumber: Dokumentasi peneliti 2020

Gambar 5. Mangkok Birma

Mangkok birma pada abad 18 ini merupakan koleksi museum kekhatuan semaka yang masih terjaga baik.

Kemudian ada beberapa koleksi museum kekhatuan semaka yang lain dalam tabel berikut: 
Tabel 1. Koleksi Museum Kekhatuan Semaka

\begin{tabular}{|c|c|}
\hline No & Koleksi \\
\hline 1. & Kussa \\
\hline 2. & Apai Kelingi \\
\hline 3. & Tikhai Sawang \\
\hline 4. & Artefak Peninggalan Anak Tuming \\
\hline 5. & Pavak \\
\hline 6. & Kundil Brunuk \\
\hline 7. & Kaiang Khui \\
\hline 8. & Tuping Sakura \\
\hline 9. & Rekhambu \\
\hline 10. & Khuniu \\
\hline 11. & Dan lain-lain \\
\hline
\end{tabular}

Sebenarnya masih banyak lagi keleksi musem kekahtuan semaka yang lainnya. Melihat beberapa koleksi tersebut dapat kita sadari bahwa museum kekahtuan semaka ini memanglah sebuah museum yang menjadi salah tempat yang melestarikan hasilhasil kebudayaan masyarakat lampung masa lampau.

\section{Pemanfaatan koleksi museum kekhatuan semaka sebagai sumber belajar sejarah}

Pemanfaatan museum sebagai sumber belajar sebenarnya dapat memberikan respon yang positif dalam pembelajaran sejarah, baik sejarah lokal, sejarah nasional maupun sejarah dunia (Yusuf, et.al, 2018). Pemanfaatan museum sebagai sumber belajar sejarah siswa menajadi salah satu inovasi yang perlu dicoba dalam proses pembelajaran sejarah, agar siswa menjadi tidak bosan dalam pembelajaran. Dalam pembelajaran sejarah di kelas dengan memanfaatakan museum kekhatuan semaka sebagai sumber sejarah adalah dengan penyusunan rencana pembelajaran. Karena sukses atau tidaknya suatu pembelajaran dikelas ditentukan dari keberhasilan seorang guru dalam menyusun rencana pembelajaran (Hartati, 2016). Rencana pembelajaran disusun dengan materi yang berkaitan dengan museum kekhatuan semaka yakni materi sejarah peminatan kelas X semester ganjil, judul materi pokok adalah "Sumber Sejarah", Kopetensi Dasar yang digunakan adalah menganalisis berbagai bentuk/jenis sumber sejarah.

Setelah memilih materi dan menentukan KD seorang guru dapat memilih metode pembelajaran yang digunakan. Metode pembelajaran yang digunakan sebaiknya membuat siswa lebih aktif dalam proses pembeljaran atau student center. Sehingga proses pembelajaran akan berpusat pada siswa. Selanjutnya adalah kegiatan pembelajaran dapat dipilih dengan dua acara, cara pertama adalah menghadirkan koleksi museum kekhatuan semaka kedalam kelas dalam bentuk foto mapun video. Cara kedua adalah kunjungan langsung ke museum kekhatuan semaka untuk mengamati koleksi-koleksi museum secara langsung.

Pemanfaatan museum kekhatuan semaka sebagai salah satu media dalam pembelajaran akan menjadikan siswa lebih mengenal warisan budaya daerahnya, sehingga memperkenalkan peserta didik akan benda-benda bersejarah yang ada di lampung. Dengan memanfaatkan museum ini sebagai sumber belajar sejarah juga akan membangun kesadaran siswa tentang pentingnya menjaga warisan budaya nenek moyang.

\section{Strategi Museum kekhatuan semaka dalam mempromosikan diri.}

Bentuk promosi yang dilakukan museum kekhatuan semaka dalam memperkenalkan diri, dilakakukan dengan berbagai cara, salah satunya adalah melalui festival budaya yang dilakukan setiap tahun. Sebagaimana disampaikan oleh informan bahwa, “... promosi museum kekhatuan semaka sudah kita lakukan, diantaranya dengan mengadakan festival tahunan dan ada beberapa penelitian dari univeristasuniversitas ke museum ini" (Wawancara Pribadi AS, 21 Januari 2020). Dalam festival ini akam coba ditampilan berbagai pertunjukan budaya lampung dan sekaligus 
memperkenalkan museum kekhatuan semaka kepada masyarakat.

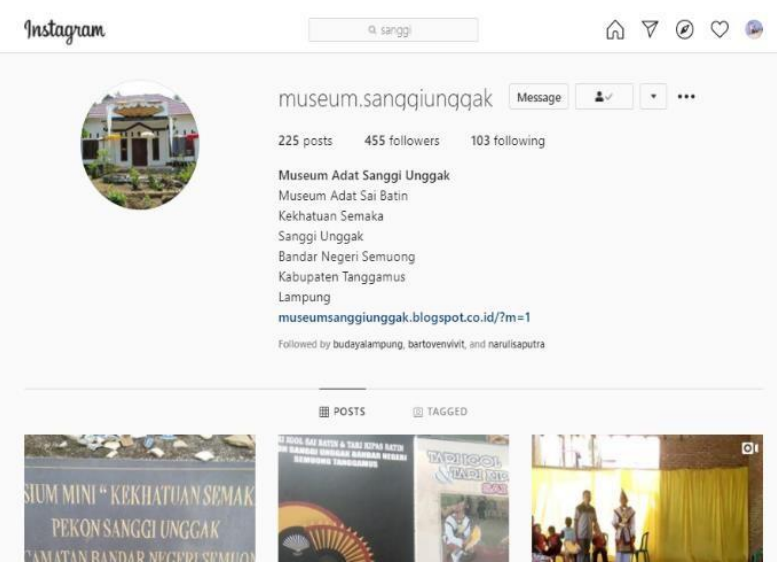

Gambar 6. Akun Instagram Museum

Upaya lain yang dilakukan untuk memperkenalkan museum kekhatuan semaka ini ke masyarakat adalah dengan media sosial Instagram. Dalam akun tersebut sudah sebanyak 225 foto yang di post, semuanya berkaitan dengan museum kekhatuan semaka baik koleksi maupun kunjungan yang dilakukan oleh beberapa instansi ke museum kekhatuan semaka. Jumlah followers yang mengikuti akun ini sampai sekarang adalah sebanyak 455 followers. Hal ini menunjukan sudah mulai banyak masarakat yang mengetahui akan keberadaan museum kekhatuan semaka ini. dengan promosi yang cukup aktif dilakukan oleh pihak museum, berdampak pada mulai banyak kunjungan ke museum ini. beberapa instansi yang telah melakukan kunjungan ke museum ini diataranya adalah universitas Lampung, UIN Radin Intan Lampung, Pemda Tanggamus, UMPRI, dan masih banyak lagi. Selain tempat wisata sejarah museum ini juga sebagai tempat penelitian dari beberapa universitas tersebut.

\section{KESIMPULAN}

Berdasarkan hasil pembahasan di atas dapat disimpulkan bahwa: 1) Pengelolaan museum kekhatuan semaka dilakukan oleh pemilik museum secara mandiri dan Koleksi museum meliputi benda-benda peninggalan sejarah dan benda-benda hasil kebudayaan lampung; 2) Pemanfaatan koleksi museum kekhatuan semaka sebagai sumber belajar sejarah adalah dengan mengaitkannya dengan KD dan materi pembelajaran sejarah; 3) Bentuk promosi yang dilakukan museum kekhatuan semaka melalui media sosial dan festival tahunan.

\section{DAFTAR PUSTAKA}

Asmara, D. 2019. "Peran Museum dalam Pembelajaran Sejarah". Kaganga: Jurnal Pendidikan Sejarah Dan Riset Sosial-Humaniora, 2(1), 10-20.

Hartati, U. 2016. "Museum Lampung sebagai Media Pembelajaran Sejarah". HISTORIA: Jurnal Program Studi Pendidikan Sejarah, 4(1), 1-10.

Hasan, S. H. 2012. "Pendidikan sejarah untuk memperkuat pendidikan karakter". Paramita: Historical Studies Journal, 22(1)

Hasan, M. Iqbal. 2002. Pokok-pokok Materi Metodologi Penelitian dan Aplikasinya. Bogor: Ghalia Indonesia.

Meihan, A. M. 2019. "Historical Learning Media Based on Mobile Learning". HISTORIKA, 23(1), 1-13.

Meihan, A. M., Sariyatun \& Ardianto, D. T. 2020. "Potensi Mobile Learning Berbasis 
Kearifan Lokal Museum Kekhatuan Semaka Dalam Pembelajaran Sejarah". In Prosiding Seminar Nasional Rekarta 2020 (pp. 1-8).

Miles M.B \& Huberman A.M. 1992. Analisis Data Kualitatif. Jakarta: UI Press

Romadi, R., \& Kurniawan, G. F. 2017. "Pembelajaran Sejarah Lokal Berbasis Folklore Untuk Menanamkan Nilai Kearifan Lokal Kepada Siswa”. Sejarah dan Budaya: Jurnal Sejarah, Budaya, dan Pengajarannya, 11(1), 79-94.

Sayono, J. 2015. "Pembelajaran Sejarah di Sekolah: Dari Pragmatis ke Idealis". Jurnal Sejarah dan Budaya, 7(1), 9-17.

Subakti, Y. R. 2010. "Paradigma Pembelajaran Sejarah Berbasis Konstruktivisme". Jurnal SPPS, 24(1), 31-53.

Sugiyono. 2017. Metode Penelitian Pendidikan (Pendekatan Kuantitatif, Kualitatif, dan $R \& D)$. Bandung: Alfabeta.

Sumadio, Bambang, 1997. Bunga Rampai Permuseuman. Jakarta: Depdikbud.

Sumanto. 2014. Teori dan Aplikasi Metode Penelitian. Jakarta: Center of Academic Publishing Service.

Susrianto, E. 2012. "Peranan Pendidikan Sejarah dalam Membangun Karakter Bangsa". LENTERA (Jurnal IImu-IImu Sejarah, Budaya Dan Sosial), 1(5), 33-44.

Sutaarga, Amir. 1991. Studi Museologi. Jakarta: Proyek Pembinaan Museum

Yusuf A.M., Ibrahim, N., \& Kurniawati. 2018. "Pemanfaatan Museum sebagai Sumber Belajar dalam Pembelajaran Sejarah”. Visipena Journal, 9(2), 215-235. 